Revue des patrimoines

40 | 2019

Lits historiques. Première anthologie des lits européens du XVe au XIXe siècle

\title{
Les lits de Louis XIII à Versailles. Entre sobriété et majesté : manifeste d'un dessein royal
}

Louis XIII's Beds at Versailles, Between Sobriety and Majesty, a Manifesto of Royal Intentions

\section{Vivien Richard}

\section{OpenEdition}

Journals

Édition électronique

URL : http://journals.openedition.org/insitu/23725

DOI : $10.4000 /$ insitu. 23725

ISSN : 1630-7305

\section{Éditeur}

Ministère de la Culture

\section{Référence électronique}

Vivien Richard, «Les lits de Louis XIII à Versailles. Entre sobriété et majesté : manifeste d'un dessein royal », In Situ [En ligne], 40 | 2019, mis en ligne le 18 septembre 2019, consulté le 14 novembre 2019. URL : http://journals.openedition.org/insitu/23725 ; DOI : 10.4000/insitu.23725

Ce document a été généré automatiquement le 14 novembre 2019.

\section{(i) $\odot$

In Situ Revues des patrimoines est mis à disposition selon les termes de la licence Creative Commons Attribution - Pas d'Utilisation Commerciale - Pas de Modification 4.0 International. 


\title{
Les lits de Louis XIII à Versailles. Entre sobriété et majesté : manifeste d'un dessein royal
}

\author{
Louis XIII's Beds at Versailles, Between Sobriety and Majesty, a Manifesto of \\ Royal Intentions
}

Vivien Richard

1 Qui évoque « lit » et « Versailles » pense au lit reconstitué en 1980 dans la chambre de Louis XIV, parfois à celui installé par Louis-Philippe dans la même pièce lors de l'ouverture du musée (aujourd'hui placé dans le salon de Mercure), voire à la présence d'une chambre à coucher de Louis XV et de Louis XVI, mais rarement aux lits méconnus de Louis XIII ${ }^{1}$. Si ceux-ci n'existent plus et n'ont donné lieu à aucune représentation iconographique, des sources permettent en quelques touches de les esquisser et d'interroger leurs usages et symboliques propres.

2 La majesté, essence du pouvoir, se conçoit en représentation. Le lit, emblème de la puissance royale et de la continuité dynastique, en est l'écrin par excellence. À son origine, le projet versaillais en semble bien éloigné. La recherche d'une vie plus retirée et les goûts relativement simples de Louis XIII ont des conséquences immédiates sur l'aménagement et l'ameublement de son appartement, dont le lit, par un jeu de métonymies, est le meilleur révélateur.

\section{Le lit du pavillon (1624-1631)}

Louis XIII, à l'instar de son père, apprécie la chasse dont il est «un jeune roi passionné $»^{2}$. Soldat dans l'âme, il se préoccupe par ailleurs peu des questions de confort et goûte simplicité et retraite. Le début des années 1620 est une période qui le conduit progressivement à être pleinement « roi en son royaume $»^{3}$ (fig. 1). Intéressé par les questions architecturales depuis l'enfance ${ }^{4}$, il est à la recherche depuis plusieurs années d'une résidence personnelle ${ }^{5}$, « petite, pour n'y admettre que peu de gens, et 
n'estre point troublé dans le repos qu'il y cherchait loin des importunitéz de la cour, et afin d'estre plus libre dans l'exercice de ses chasses, lors qu'il s'y voulait addonner $»^{6}$.

Figure 1

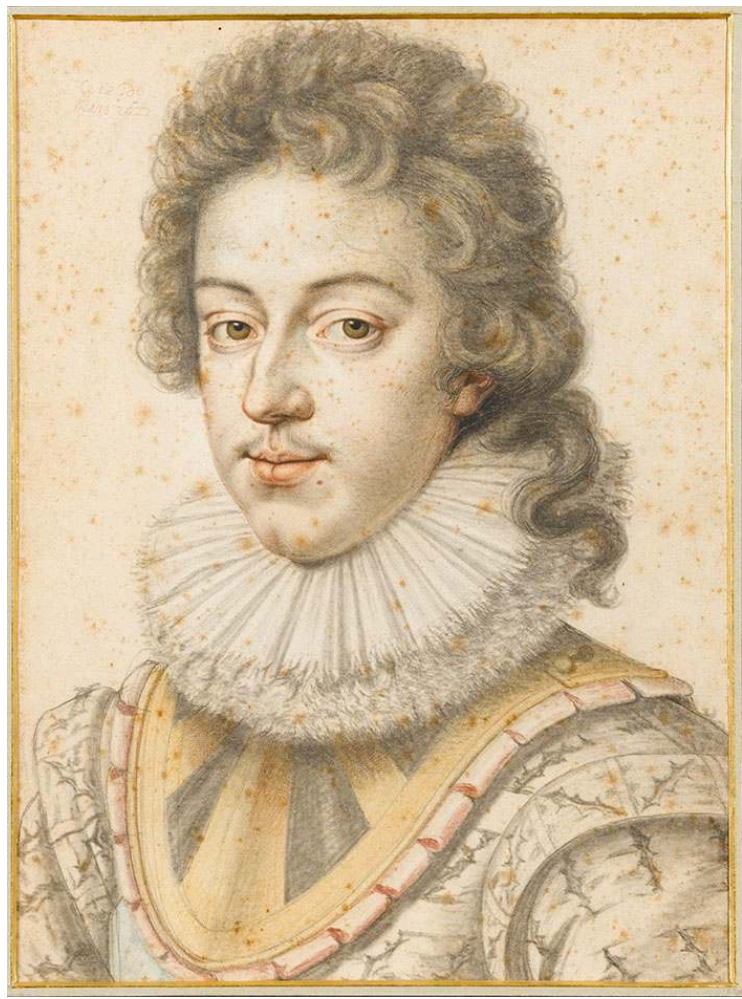

Portrait de Louis XIII, par Daniel Dumonstier, 1622. Chantilly, musée Condé, inventaire PD 383

(c) RMN-Grand Palais (domaine de Chantilly).

En 1623, son choix se porte sur le bourg de Versailles ${ }^{7}$. Ses environs ne sont pas inconnus du roi qui a eu l'occasion d'y chasser au moins cinq fois depuis sa toute première chasse partie de Noisy et achevée à Versailles en $1607^{8}$. Dès l'été 1623 , le sommet de la butte est choisi pour édifier une «maison des champs ». Au milieu d'une plateforme se dressent trois corps de bâtiment en plan carré, avec le corps de logis principal à l'ouest et deux ailes en retour, au nord et au sud. Le pavillon semble bâti à l'économie - dimensions réduites et faible coût de construction obtenu par l'emploi de moellons, mortier de chaux et sable, bois et plâtre - mais présente également un caractère de qualité - bossages, toit d'ardoise - qui reflète le statut de son propriétaire. Ainsi, dès le projet initial apparaît la tension inhérente au Versailles de Louis XIII, entre simplicité personnelle et caractère royal.

5 L'édification est rapide. Louis XIII vient à plusieurs reprises sur le chantier. Dans son Journal, son premier médecin Jean Héroard relate au 9 mars 1624 la première nuit que le souverain passe à Versailles : «Va après voir son bastiment. À sept heures, soupé [...] Va en sa chambre. Faict faire son lict qu'il avait envoié quérir à Paris ; il y aide luymesme [...] Beu de l'eaue avec du syrop de cerises. À onze heures, mis au lict. Prie Dieu ; s'endort soubdain jusques à cinq et demie après minuict ${ }^{9}$. " (fig. 2) Le bois de lit, la couche et la garniture ont été amenés, sans doute, du Louvre ou du garde-meuble de Paris. Louis XIII dort dans une chambre totalement vide, aux plâtres et peinture frais et 
où seul est installé son lit, peut-être accompagné de paillasses pour des compagnons ${ }^{10}$. Le premier séjour a lieu trois mois plus tard, du 27 juin au 5 juillet $1624^{11}$.

Figure 2

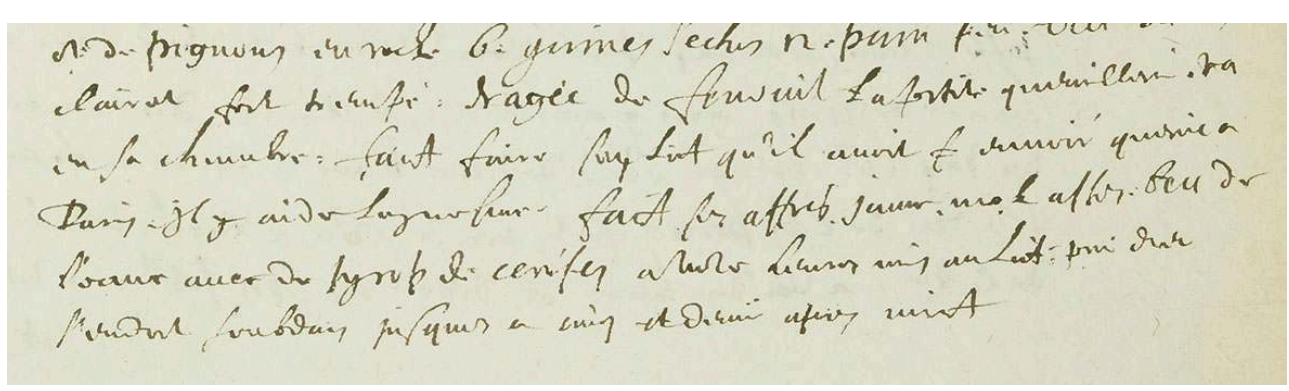

Journal de Jean Héroard, 9 mars 1624. BnF, Ms., Français 4027, fol. $173 r^{\circ}$, détail. (c) BnF.

\section{La chambre et le lit du roi}

Le premier étage du corps de logis est dévolu au roi. Sa distribution est certaine grâce aux recoupements des devis de construction de 1623 et de 1631 et de l'inventaire des meubles de $1630^{12}$. L'appartement du roi se développe de part et d'autre de l'escalier. À gauche se trouvent la chambre et le cabinet, à droite, la salle et la garde-robe, écho à la traditionnelle dichotomie entre chambre et salle. La description des espaces est rendue possible grâce aux écrits théoriques de Pierre Le Muet, possible architecte de Versailles, et de Louis Savot $^{13}$. De forme presque carrée avec 19 pieds de longueur $(6,21 \mathrm{~m})$ sur 18 pieds de largeur $(5,88 \mathrm{~m})$ pour $36,5 \mathrm{~m}^{2}$, la chambre compte deux croisées sur la cour et deux sur le jardin ${ }^{14}$. Trois portes régissent les circulations : deux du côté de la cour pour accéder au cabinet et au palier de l'escalier, et une troisième qui, par un passage en biais, conduit à la galerie de l'aile sud. La cheminée est sur le mur sud, mitoyen du cabinet, accueillant le lit dans l'angle disponible. Il est donc possible de formuler une hypothèse sur la façon dont était structuré ce mur de 18 pieds $(5,88 \mathrm{~m})$ qui accueille le lit $^{15}$. En partant de l'est, le premier pan de mur occuperait 1 pied 1 pouce 6 lignes $(0,37 \mathrm{~m})$. Suivrait la porte de communication avec le cabinet de 2 pieds 6 pouces $(0,82 \mathrm{~m})$, donc peut-être à un seul vantail. Un second pan de mur lui ferait suite avec 1 pied 1 pouce 6 lignes $(0,37 \mathrm{~m})$. La cheminée compterait 4 pieds 6 pouces de long $(1,47 \mathrm{~m})$. Le lit, de 4 pieds 6 pouces de large $(1,47 \mathrm{~m})^{16}$, serait placé contre la cheminée, source de chaleur directe, et se trouverait donc à l'opposé des trois portes de la pièce et ainsi à l'abri des vents coulis. Puis la ruelle viendrait clore le pan de mur avec ses 4 pieds 3 pouces $(1,39 \mathrm{~m})$ : une chaise percée peut donc y être placée.

On ne sait rien de l'aménagement et de la décoration de la pièce durant les premières années du pavillon. De 1624 à 1630, les sources sont muettes. L'inventaire des meubles, réalisé en 1630 à la mort du concierge François Mongé, rompt ce silence ${ }^{17}$. Le meuble de la chambre, alors un meuble d'été, affiche une belle unité de damas vert aux franges de soie verte et d'or. Le lit est « garni de son bois de lict, [de] trois matelaz de futaine de boure-lanice, [d']ung traversin de futaine plain de duvet, [d]'une enveloppe de fustaine, [d']une couverture de thoille Haulande picquée, [de sa] housse de damas garnye, de trois rideaux, [de] quatre bonnes grasses, $[\mathrm{du}]$ fond et [du] dossier, [d']une couverture de parade, [de] quatre pommes de damas [et d']ung orillier de velours vert » (fig. 3). 
Figure 3

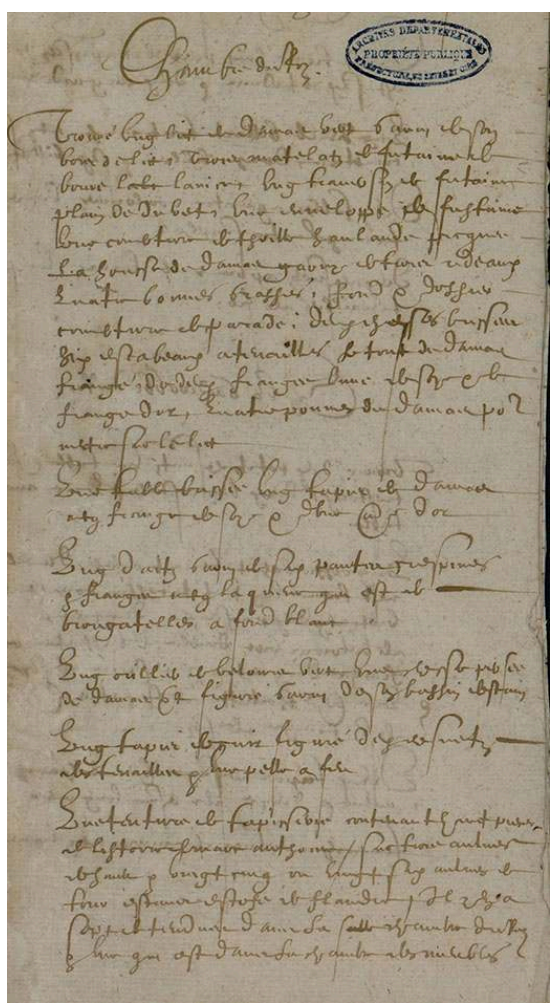

Inventaire des meubles du roi au château de Versailles, 24 septembre 1630. AD Yvelines, B 3586, fol. $2 r^{\circ}$.

(c) AD Yvelines.

8 Le lit, « à la française ", présente donc un chevet unique dont le dossier est placé contre le mur. Le bâti est entièrement recouvert de tissu. Quatre colonnes soutiennent l'impériale, de mêmes dimensions que le châssis, où prend place la couche composée ici de trois matelas, de deux couvertures, d'un traversin et d'un oreiller. Le même damas recouvre les quatre pommes de bois des angles de l'impériale, ainsi qu' « une chesse persée garni de son bassin d'estain » et le tapis d'une table brisée, tapis sans doute en housse pour éviter les plis aux angles ${ }^{18}$. Au lit s'ajoutent enfin « deux chesses brissées, six escabeaux à tenailles ", alignés le long des murs. Les dimensions du lit ne sont pas données par l'inventaire de 1630. Mais celui de 1666 et le premier inventaire général des meubles de la Couronne comptent un meuble très proche, alors partiellement conservé et considéré «fort vieux» et "en désordre " ${ }^{19}$. Ses fauteuils sont «meschands» et les pliants manquent. Le « vieux bois» de lit fait 4 pieds 6 pouces de large $(1,47 \mathrm{~m})$. Selon les préconisations de Louis Savot, pour 4 pieds $1 / 2$ de large, le lit peut atteindre 6 pieds 9 pouces $(2,2 \mathrm{~m})$ de hauteur ${ }^{20}$ (fig. 4, fig. 5). 
Figure 4

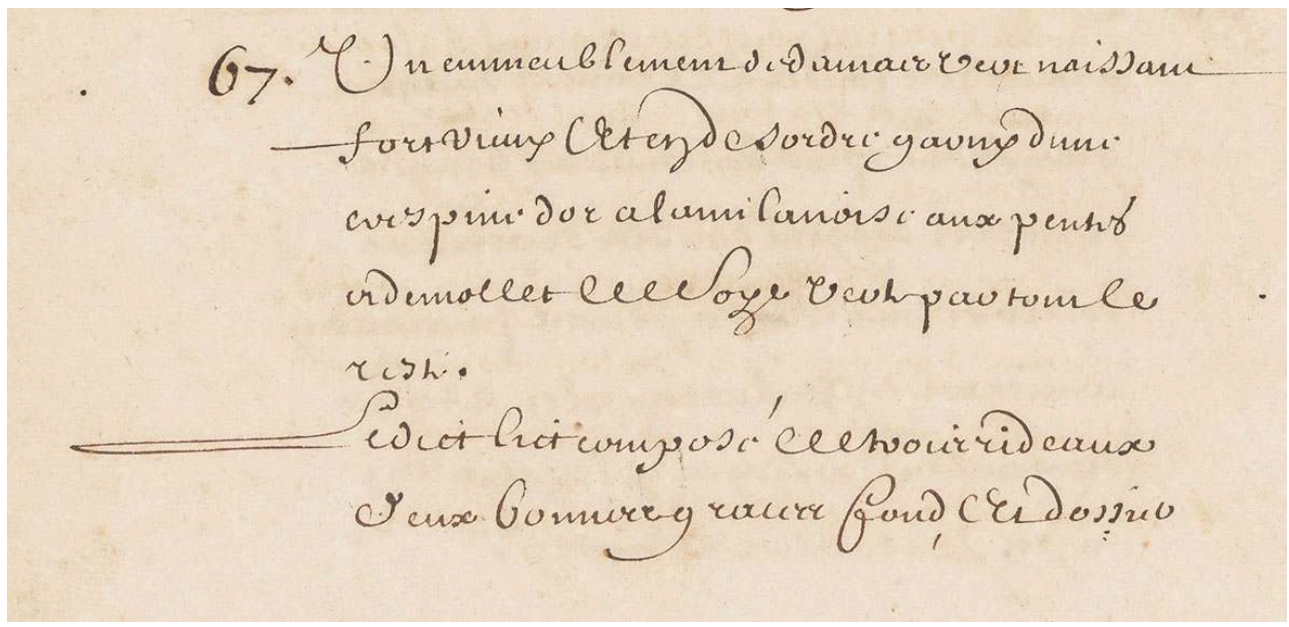

Inventaire des meubles du château de Versailles (1666-1684). AN, O 3450, fol. 61 vº, détail. (c) AN/pôle Image.

Figure 5

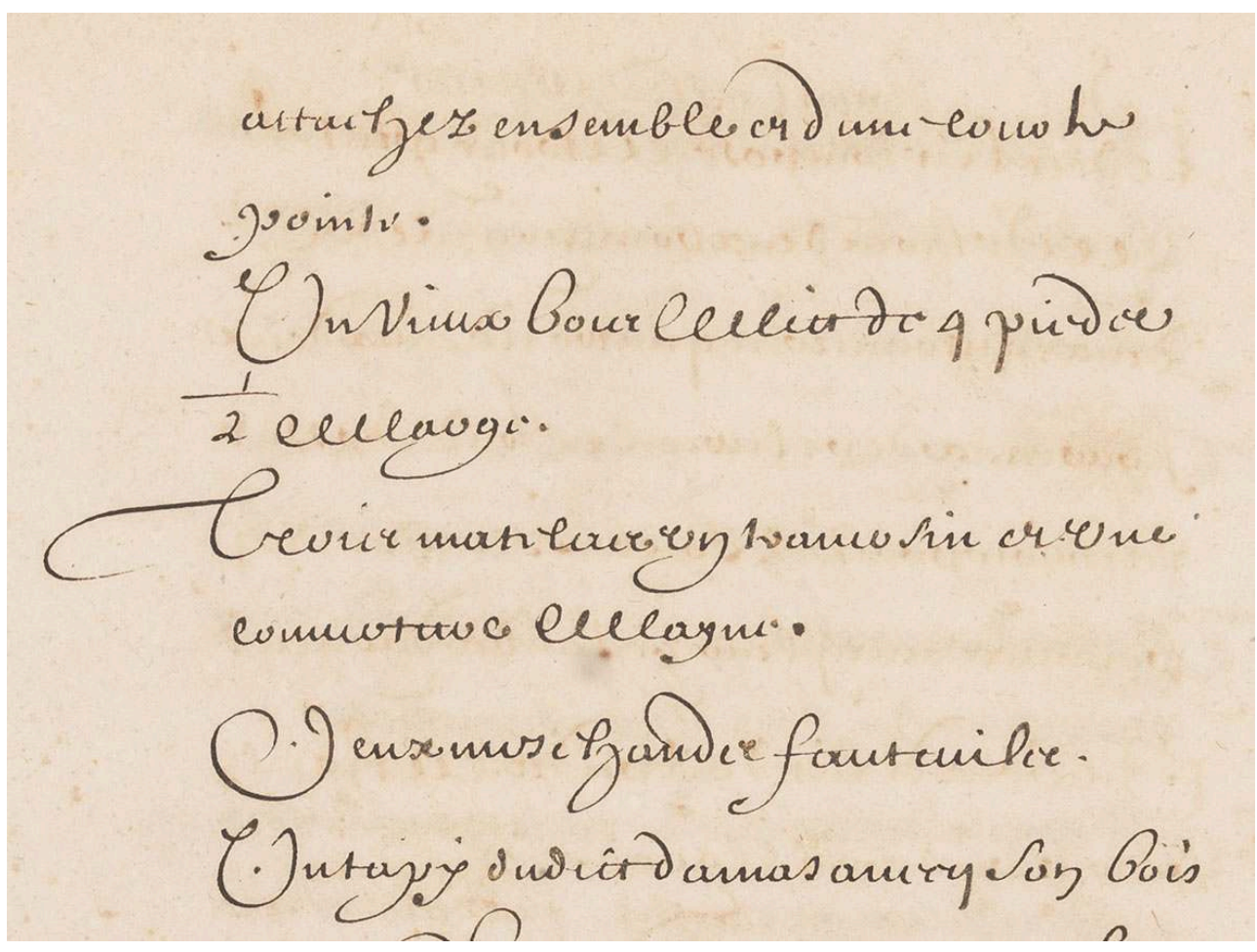

Inventaire des meubles du château de Versailles (1666-1684). AN, $0^{1} 3450$, fol. 62ro détail.

(c) AN/pôle Image.

Il est possible d'avoir une idée approchante d'un tel meuble. En effet, en chemin le 14 juillet 1622 entre Alzonne et Carcassonne, en Languedoc, Louis XIII a fait halte au château de Pennautier et aurait offert son meuble de campagne à Bernard de Pennautier. Ce meuble, en laine et bourre de soie, est composé d'un lit complet, de ses étoffes et six fauteuils. Il est toujours conservé au château de Pennautier (Aude) et inscrit au titre des monuments historiques. Cet ensemble aux motifs de grotesques, 
carquois et cornes d'abondance, en usage deux ans avant la première installation de Louis XIII à Versailles et dont les dimensions concordent, donne un aperçu d'un meuble ayant réellement appartenu à Louis XIII et adapté à la vie qu'il souhaitait mener dans son pavillon ${ }^{21}$ (fig. 6, 7, 8).

Figure 6

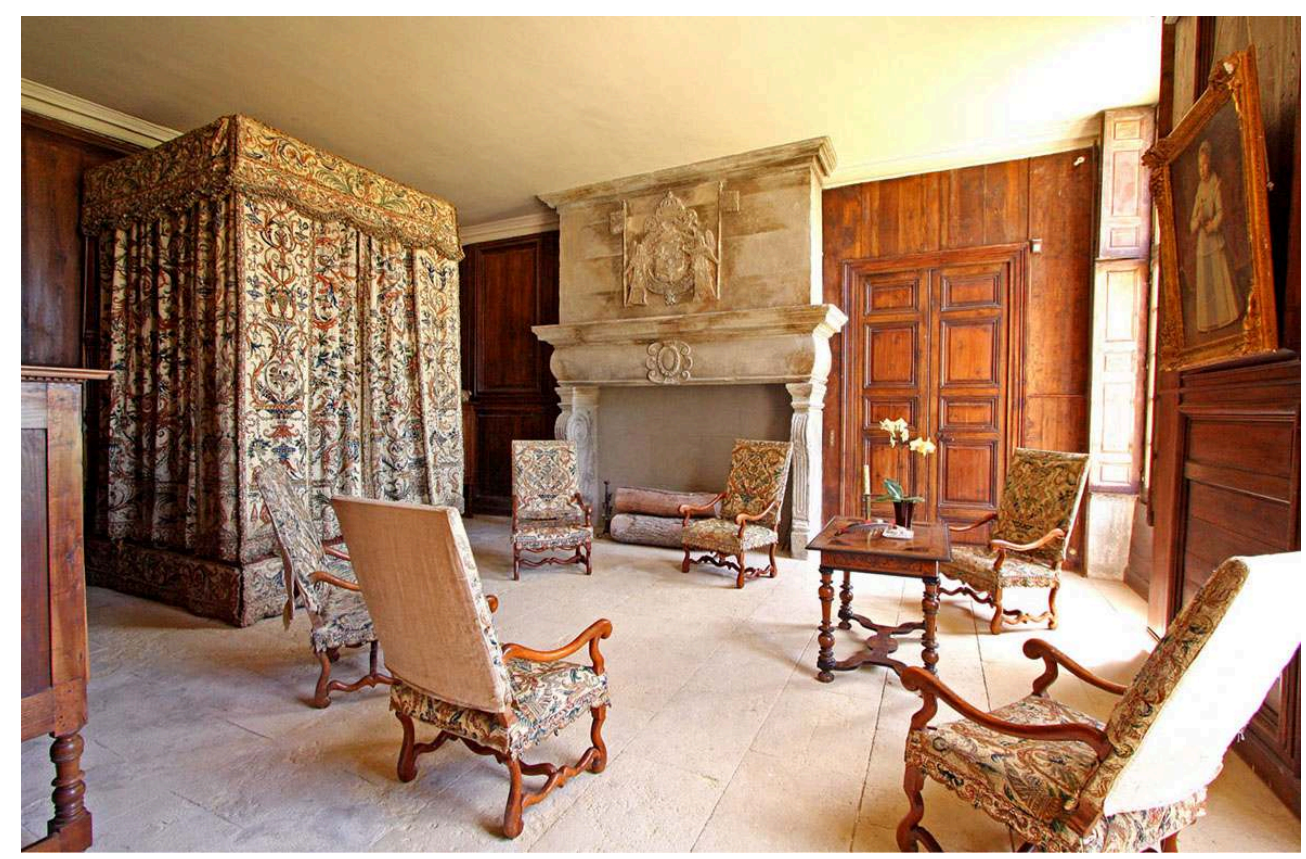

Chambre, dite de Louis XIII, au château de Pennautier (Aude), état 2018.

(c) Lorgeril.chateaudepennautier. 
Figure 7

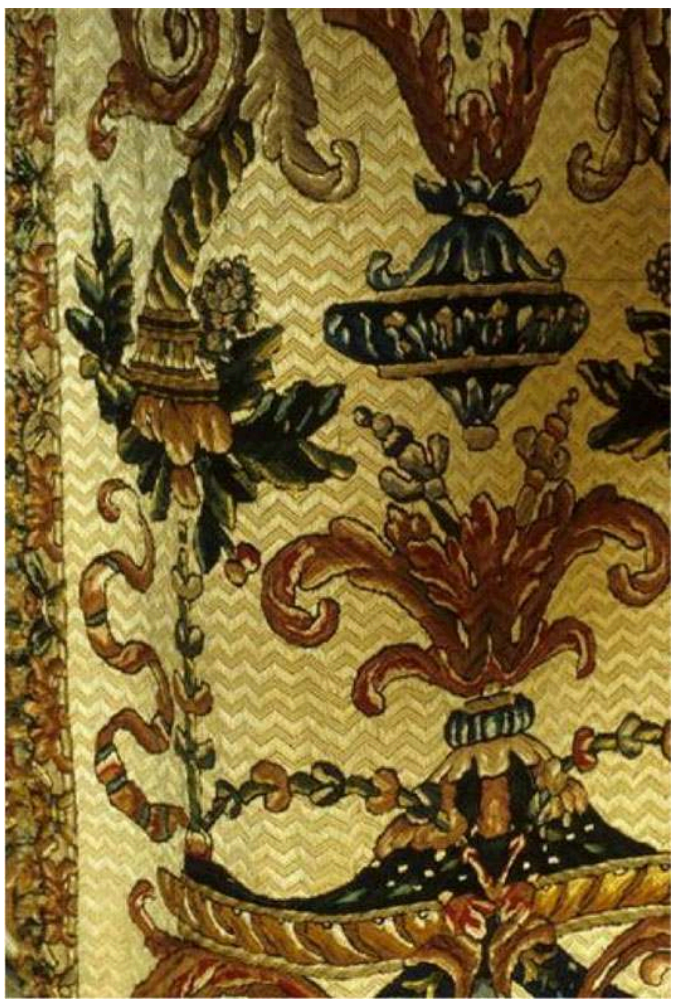

Détail du meuble de la chambre dite de Louis XIII au château de Pennautier (Aude), 1988.

Phot. André Signoles. (c) Monuments historiques.

Figure 8

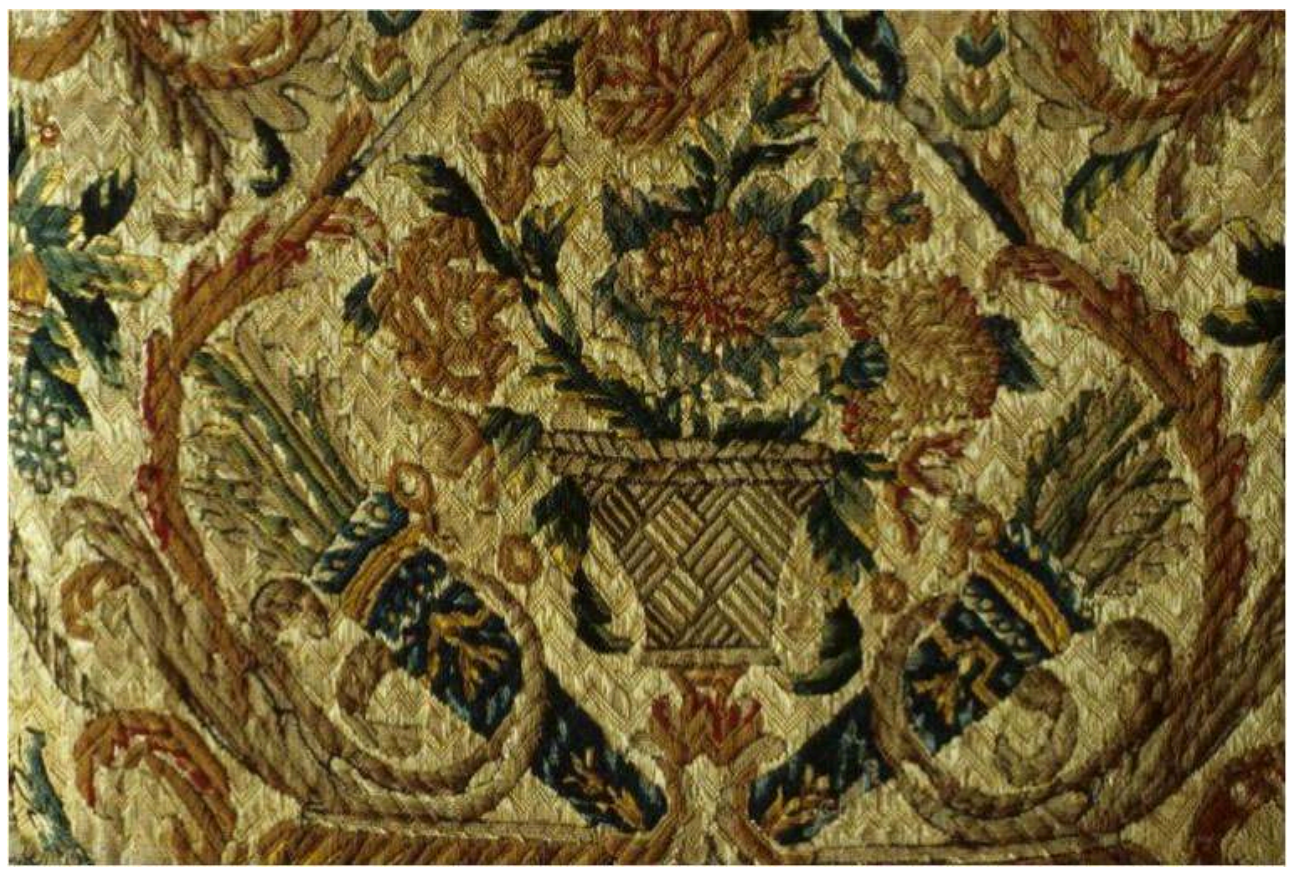

Détail du meuble de la chambre dite de Louis XIII au château de Pennautier (Aude), 1988.

Phot. André Signoles. (c) Monuments historiques. 
10 À Versailles, au côté du lit, la chambre est marquée par la présence du dais royal « garni de six pantes, crespines et franges, avecq la queue qui est de brougatelles à fond blanc " (voir fig. 3). Placé sans doute en face de la cheminée, il est avec le lit le symbole du pouvoir souverain du maitre des lieux. Leur présence conjointe les renforce l'un l'autre. Les murs sont, quant à eux, tendus d'" une tenture de tapisserie contenant huict pièces de l'istoire de Marc-Anthoine sur trois aulnes de hault et vingt-cinq ou vingt-six aulnes de tour, estans estofe de Flandre. [...] sept de tendues dans la chambre du roy et une qui est dans la chambre des meubles » (voir fig. 3). Cette tenture a été offerte par la reinemère Marie de Médicis et reçue à Versailles le 16 décembre 1624. Le mobilier est enfin complété de la table brisée, dont le tapis de damas recouvre lui-même un tapis de cuir figuré pour en compenser la mollesse. De même, la cheminée comporte deux chenets, sans doute de fer ou de laiton, ornés de boules de cuivre, des tenailles et une pelle à feu ${ }^{22}$.

Figure 9

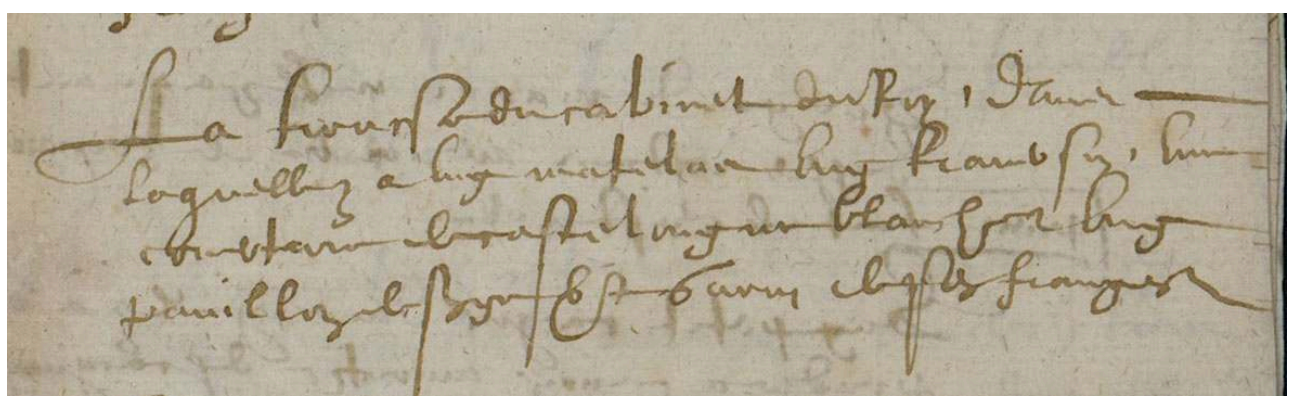

Inventaire des meubles du roi au château de Versailles, 24 septembre 1630. AD Yvelines, B 3586, fol. $7 r^{\circ}$, détail.

(c) AD Yvelines.

L'inventaire note la présence, dans deux des trois pièces servant de garde-meubles au rez-de-chaussée de l'aile sud, de «la trousse du cabinet du roy dans laquelle y a ung matelas, ung traversin, une couverture de Castelongue blanche, un pavillon de serge vert garni de ses franges » (fig. 9), c'est-à-dire le couchage pour un valet de chambre du roi qui dort dans le cabinet mitoyen de la chambre, du «tour de lict de Sa Majesté tout garni de serge verte, franjon de soye, [d']une couverture pour mectre sur le lict de Sa Ma[jesté] en yvert ", et de " cinq pièces de tapisseries de pareille et sembl[able] estofe que le daiz qui est en la chambre du roy » (fig. 10). Enfin, l'inventaire est complété par une liste de pièces de linge dont « six paires de draps de Sa Majesté » (fig. 11). 
Figure 10

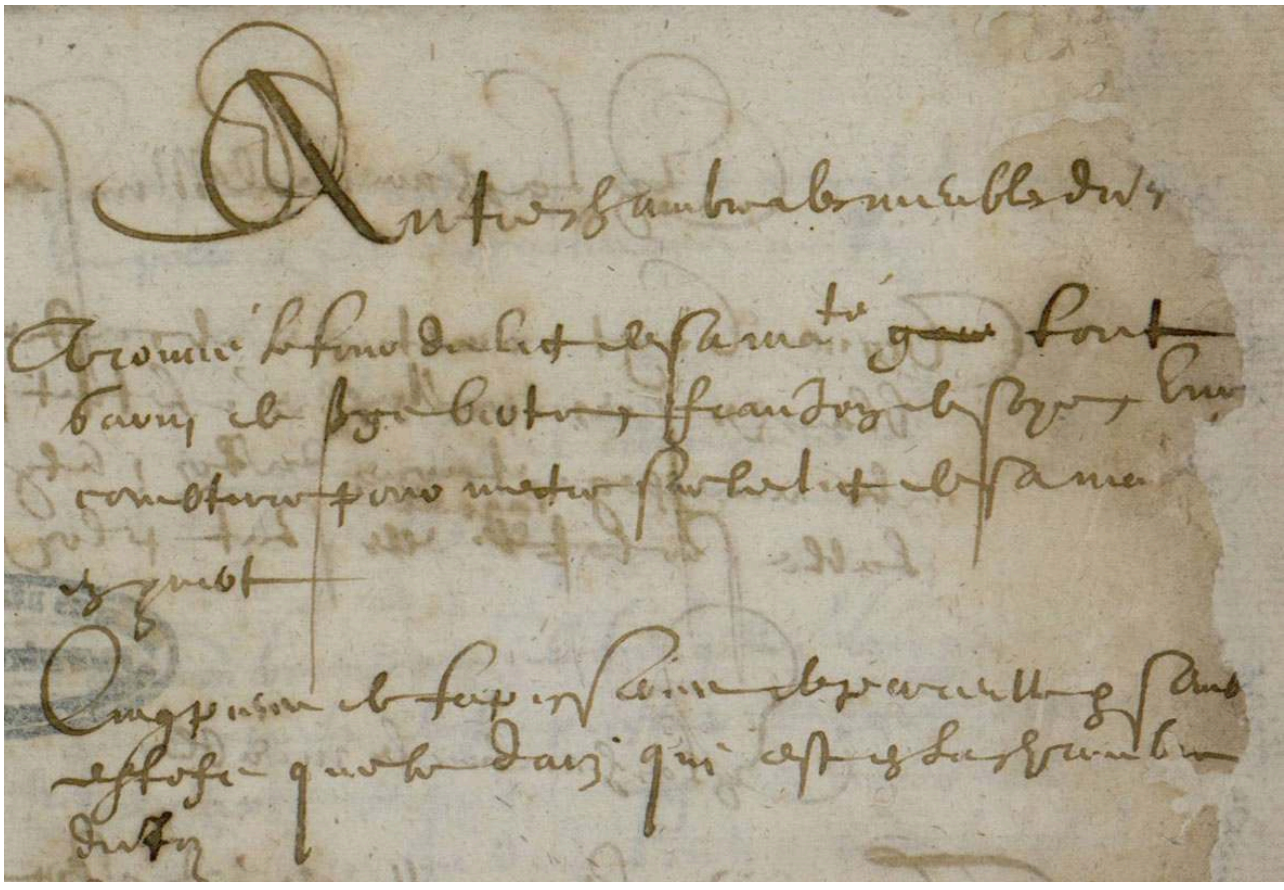

Inventaire des meubles du roi au château de Versailles, 24 septembre 1630. AD Yvelines, B 3586, fol. $7 v^{\circ}$, détail.

(c) AD Yvelines.

Figure 11

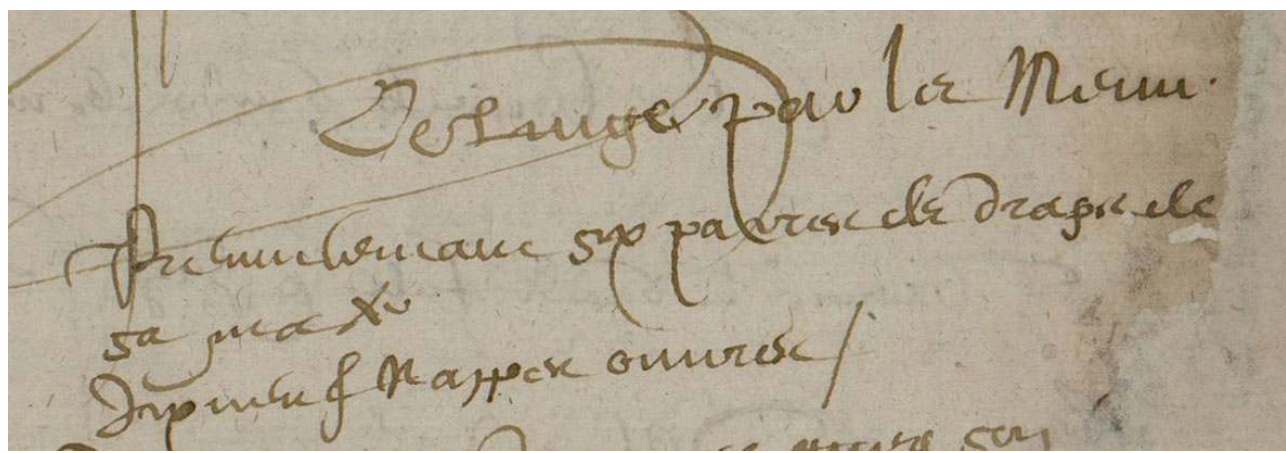

Inventaire des meubles du roi au château de Versailles, 24 septembre 1630. AD Yvelines, B 3586, fol. $9 v^{\circ}$, détail.

(C) AD Yvelines

\section{Le lit dans la vie versaillaise de Louis XIII}

Qu'ils s'appliquent au riche bourgeois comme au souverain, les statuts et rôles ordinaires de la chambre et du lit ne peuvent à Versailles que se situer à la frontière entre mobilier de l'intime et manifestation politique. La majeure partie de la vie du roi à Versailles se déroule à proximité immédiate du lit. Louis XIII dort bien plus souvent à Versailles que ne l'insinue le duc de Saint-Simon lorsqu'il énonce que « ce monarque ne couchait jamais, ou bien rarement à Versailles qu'une nuit et par nécessité $»^{23}$. Au 
contraire, il y dort au moins 31 nuits en 1627. En revanche, certaines années, les longues campagnes militaires expliquent qu'il n'y dorme qu'une poignée de nuits.

Lors de l'annonce d'une prochaine arrivée du roi, de sa suite et de sa garde, son appartement est préparé. Pour le lit, le concierge procède au nécessaire. Le tour de lit et sa couverture sont apportés. Le lit est fait avec une des six paires de drap dévolues à cet usage. La « trousse » du valet de chambre rejoint le cabinet.

La répétition des annotations d'Héroard permet d'évoquer les activités régulières de Louis XIII autour de son lit à Versailles. Il est réveillé aux aurores les jours de chasse, sinon à huit heures. Il arrive, si la chasse du lendemain débute dans la nuit, que le coucher soit anticipé, voire que le roi se couche tout habillé pour être prêt plus rapidement $^{24}$. Le soir, avant de se mettre au lit, revêtu de sa chemise de nuit, il prend une ou deux tisanes, du sirop de cerises ou du potus divinus, voire des dragées de fenouil ${ }^{25}$. La journée se conclut immanquablement par une prière au pied du lit. Durant la journée, hors maladie ou audience, il est toujours d'usage que les rideaux du lit soient tirés ${ }^{26}$. Des variantes apparaissent, selon le programme et ou le degré de fatigue du roi ${ }^{27}$. Aucune source ne montre avec autant de clarté la place du lit durant un séjour de Louis XIII à Versailles que la narration de la journée du 24 août 1627, alors que, sur la route de l'Aunis, il gagne Versailles pour se reposer après l'une des premières manifestations de la maladie de $\mathrm{Crohn}^{28}$ :

[Il] se met dans le carrosse jusque à Versaille à unze heures et ung quart. Se met auprès du feu, puis sur son lict. [Après le dîner] va en sa chambre, se couche sur son lict, se faict couvrir les jambes de sa robe fourrée, y est environ une heure. Levé, s'amuse à peindre. À trois heures et demie, se met sur le lict. À quatre heures sort [...]. Revient à cinq heures, se met au lict. Clystère laxatif, le garde demi-heure [...]. À six et demie, levé, vestu [...]. À huict heures desvestu, mis au lict [...]. Prie Dieu ; s'endort à neuf heures et demie jusques à sept et demie après minuict ${ }^{29}$ (fig. 12, fig. 13). 
Figure 12

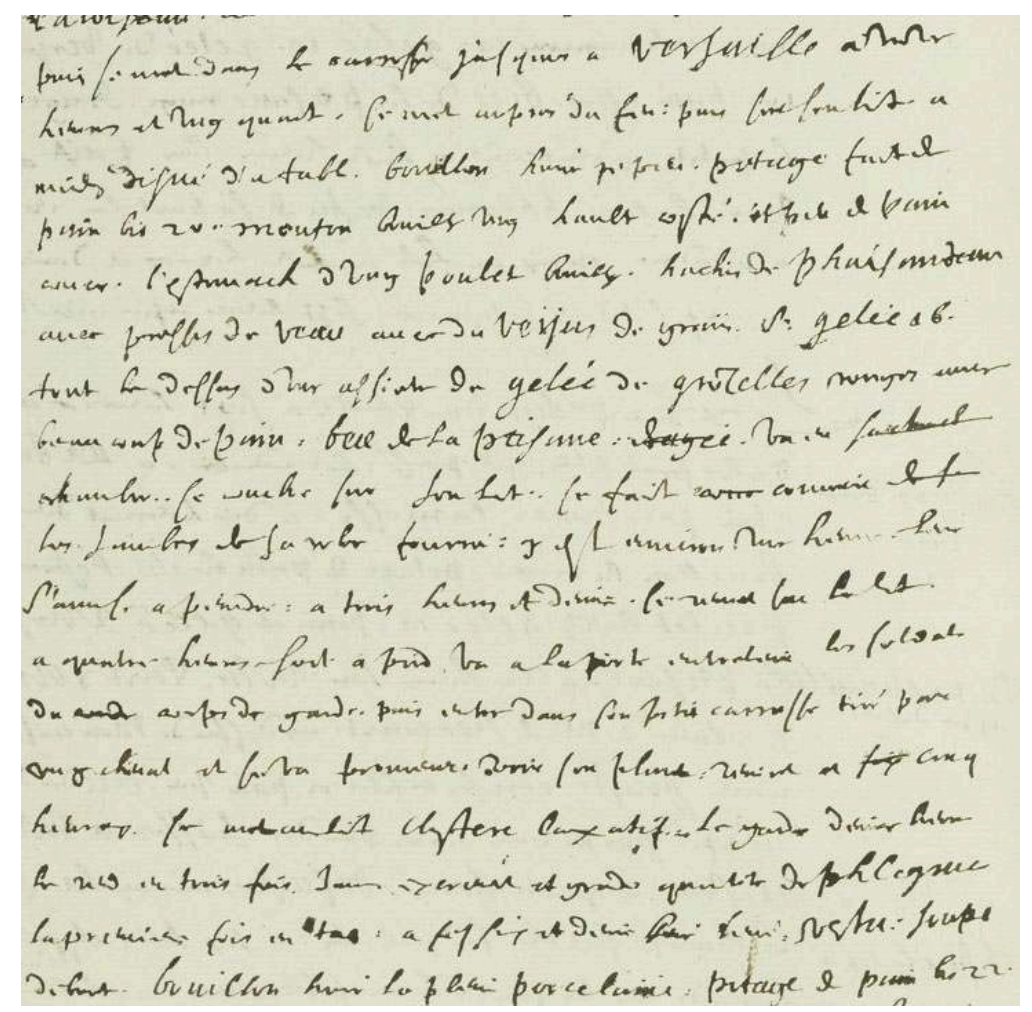

Journal de Jean Héroard, 24 août 1627. BnF, Ms., Français 4027, fol. 418vº détail. (C) BnF.

Figure 13

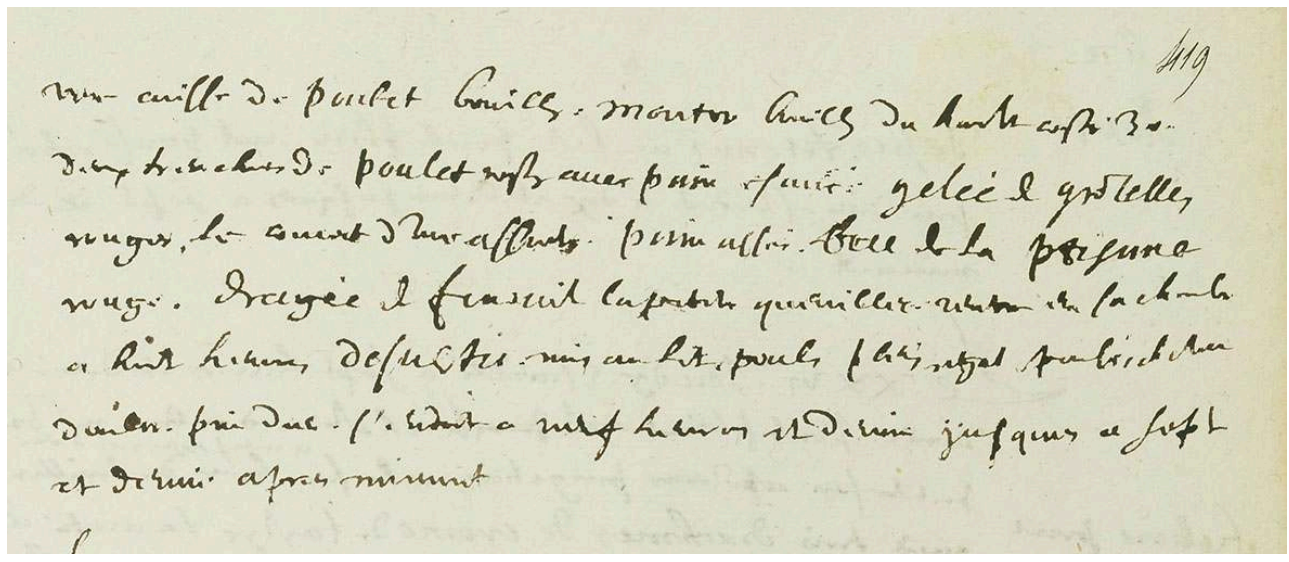

Journal de Jean Héroard, 24 août 1627. BnF, Ms., Français 4027, fol. 419rº, détail.

(c) BnF.

Versailles n'est pas qu'un lieu de repos et de chasse. Si Louis XIII ne semble pas avoir tenu conseil à Versailles avant 1630, son pavillon ne l'éloigne pour autant pas des affaires de l'État. Il y reçoit plusieurs ministres, et ce, dès $1624^{30}$. Le roi accorde aussi quelques audiences ${ }^{31}$, son fauteuil placé dos à la cheminée ou sous le dais. Le visiteur arrive par l'escalier central. En pénétrant dans la chambre du roi, il voit immédiatement la cheminée et le lit qui occupent tout l'espace visuel. Mis en valeur par l'aménagement intérieur, le lit du roi est un symbole de sa puissance et de la continuité 
dynastique. Le dais, bien qu'ici dépourvu de siège, renforce cette spatialisation de la majesté, même dans la sobre résidence privée qu'est Versailles.

La conduite de l'État vient chercher Louis XIII jusque dans son lit versaillais. En mai 1627, il est réveillé peu après son coucher pour être avisé par un courrier de Marie de Médicis de l'arrestation de François de Montmorency-Bouteville et du comte des Chapelles, en fuite depuis leur duel du 12 mai qui bafoue une fois de plus la récurrente législation royale en la matière ${ }^{32}$.

Grâce au lit et au dais, la chambre forme un tout indissociable de la majesté. L'appel pour duel commis à Versailles le 3 novembre 1626 dans la chambre du roi par Roger du Plessis-Liancourt, pourtant premier gentilhomme de la chambre, au nom du duc d'Halluin contre le marquis de Cressia, le prouve ${ }^{33}$. Les documents liés à cette affaire notent tous que ce crime de lèse-majesté est aggravé pour avoir été commis dans la chambre du roi, c'est-à-dire en ce lieu où, par la présence du lit et du dais, s'incarne la plénitude de cette majesté lésée ${ }^{34}$.

Enfin, c'est dans sa chambre que Louis XIII réinvestit le cardinal de Richelieu de toute sa confiance lors de la journée des Dupes (10 novembre 1630) ${ }^{35}$. Pendant une semaine, la pièce connaît un afflux de courtisans ${ }^{36}$. Versailles n'est déjà plus une simple résidence de repos et de chasse. Jean de La Barde, commis aux Affaires étrangères, écrit à son cousin Léon Bouthillier qu' « il semble que la monarchie soit transférée [à Versailles] » ${ }^{37}$, monarchie qui siège ainsi informellement durant huit jours dans la chambre et le cabinet du roi.

La présence dans la chambre du dais et du lit matérialise le statut du maître des lieux. Néanmoins, la taille de Versailles, une modeste maison des champs, ainsi que les goûts simples de Louis XIII, induit un mobilier moins luxueux, moins diversifié et plus rare que celui d'une traditionnelle chambre royale. La simplicité de la décoration de la chambre, pourtant pièce symbolique du pavillon, met de facto en valeur le lit de damas vert et or qui résume par lui-même le projet versaillais mis en œuvre par le roi.

\section{Le lit du château (1632-1643)}

Après la journée des Dupes, Louis XIII inclut progressivement Versailles dans la géographie du pouvoir royal. Délaissant Paris, il fait du château de Saint-Germain-enLaye le lieu où siège la Cour et de Versailles un lieu privé où il peut néanmoins recevoir. Cette décision en génère une autre, importante: l'agrandissement du pavillon. Louis XIII confie la transformation des bâtiments à Philibert Le Roy, ingénieur et architecte ordinaire des Bâtiments du roi. L'architecte s'inspire fortement de dessins de Philibert Delorme, notamment celui d'un édifice enrichi de pavillons décrochés ${ }^{38}$ (fig. 14). 
Figure 14

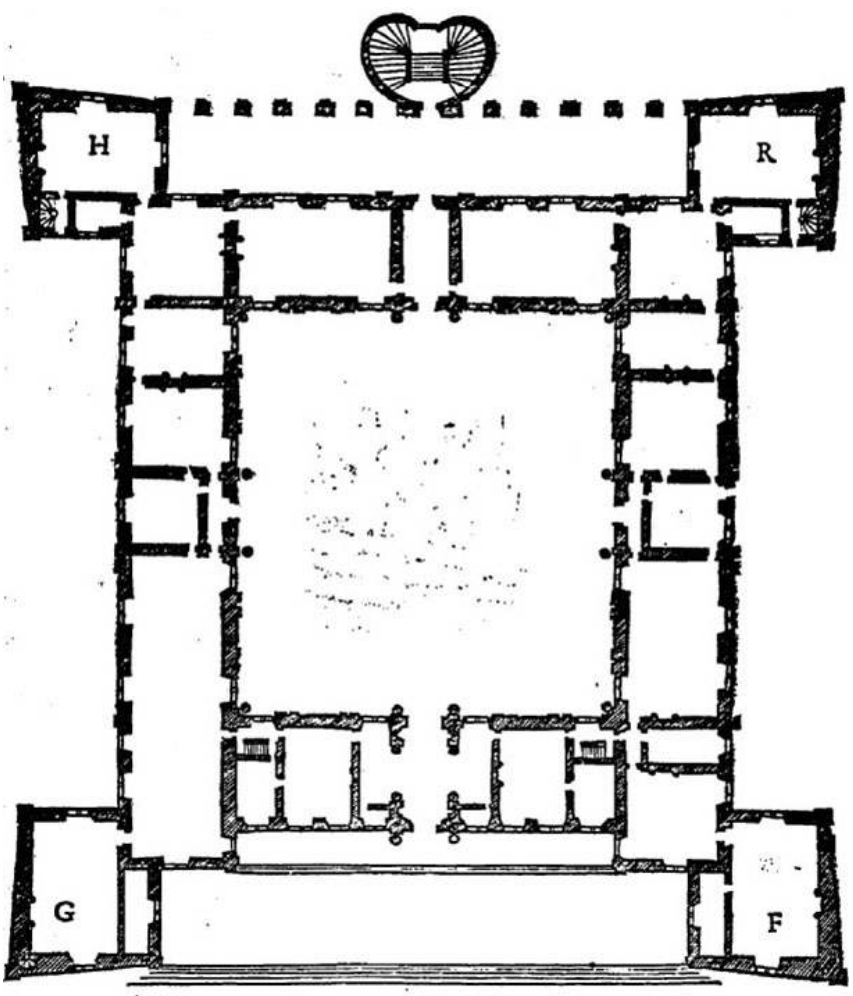

Plan d'un château aux champs proposé par Philibert Delorme dans son Premier Tome de l'architecture 1567, fol. 18ro, détail.

(C) BnF.

Le château doit présenter un corps de logis allongé et élargi, de même que les deux ailes latérales. Les façades sont de brique et pierre et les toitures d'ardoise. Le chantier s'étale du printemps 1631 à l'été 1634, sans doute pour des raisons de financement et pour que le château reste habitable. La phase de travaux du corps central dure d'avril à novembre 1631. Lorsque le roi arrive de Lorraine le 16 février 1632, Versailles est pleinement passé du statut de pavillon à celui de petit château. Son aspect global est connu par deux représentations postérieures de vingt ans mais antérieures à tous travaux de modification: une vignette du plan de Paris de Jacques Gomboust (1652) (fig. 15) et une gravure d'Israël Silvestre (datable de 1654) ${ }^{39}$ (fig. 16). 
Figure 15

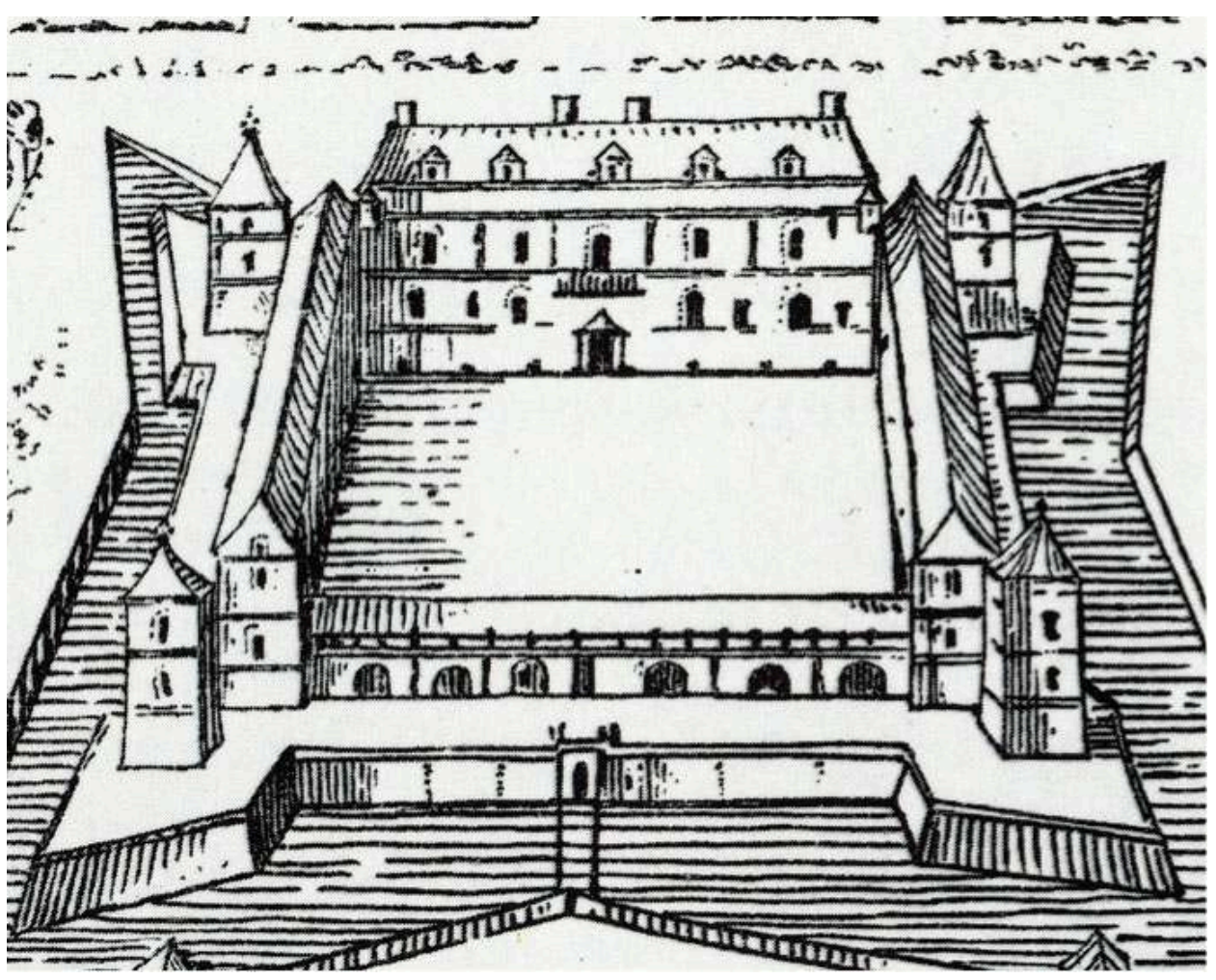

Vue cavalière du château de Versailles en 1652 : détail du plan de Paris par Jacques Gomboust. BnF, Est., Topographie de la France, Va 78 e fol., t. 2, B 9000.

(C) BnF.

Figure 16

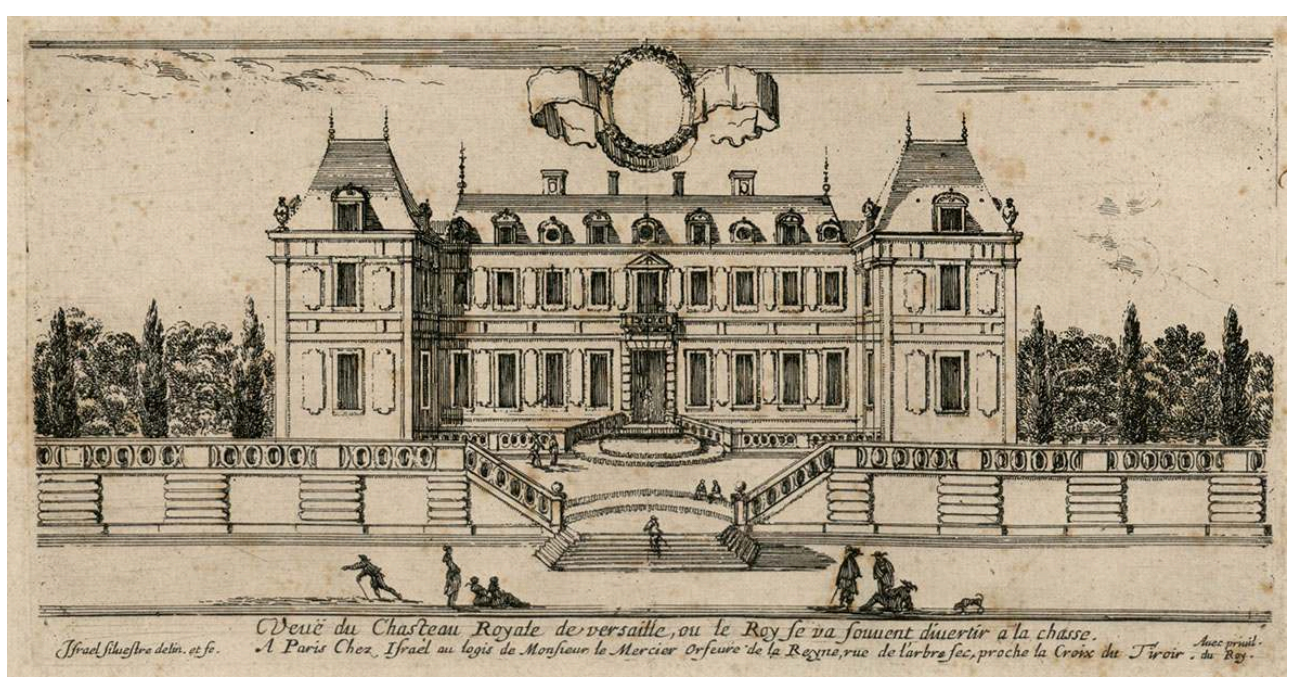

"Veue du chasteau royale de Versaille où le roy se va souvent divertir à la chasse », [1654], par Israël Silvestre. Versailles, musée national des Châteaux de Versailles et de Trianon, INV.GRAV 5663.

(c) Château de Versailles. 


\section{La nouvelle chambre et le nouveau lit de Louis XIII}

22 Le corps de logis est agrandi et non intégralement détruit ${ }^{40}$. En effet, les pièces, qui restent en enfilade simple, sont agrandies au premier étage et passent de 18 à 24 pieds (de 5,88 à 7,85 m) par la prolongation des murs extérieurs sud et nord et des murs de refend pour atteindre la nouvelle façade côté jardin. Les cheminées et les portes n'étant pas mentionnées dans le devis pour le corps de logis, on peut supposer que celles du pavillon sont maintenues ${ }^{41}$.

23 Au premier étage du corps central, Louis XIII a voulu deux appartements symétriques, de part et d'autre de l'escalier central, avec une antichambre, une chambre et un cabinet. Mais l'escalier crée par son emplacement et son volume un déséquilibre dans la superficie des deux antichambres. Celle de l'appartement nord est de $77 \mathrm{~m}^{2}$ tandis que celle de l'appartement sud, ancien appartement du roi, se limite à $48,5 \mathrm{~m}^{2}$ : Louis XIII s'installe donc dans la partie nord pour disposer de la plus grande antichambre. De celle-ci, on accède à la chambre du roi ${ }^{42}$, qui correspond à l'ancienne garde-robe aux volumes très amplifiés, atteignant désormais 24 pieds de côté $(7,85 \mathrm{~m})$, dimension idéale selon les préconisations de Pierre Le Muet et de Louis Savot ${ }^{43}$, et offre ainsi une surface de $61,5 \mathrm{~m}^{2}$. Plus lumineuse que la précédente, elle prend jour par trois fenêtres, deux donnant à l'ouest sur le parterre et une au nord. La pièce est ainsi baignée de soleil le soir, au couchant. Une porte à l'est du mur de refend communique avec l'antichambre, une seconde sur le mur est donne dans l'aile droite sur une galerie et enfin une troisième, dans l'angle nord-ouest, conduit par un pan coupé en biais vers le nouveau cabinet du roi.

La cheminée étant sur le mur sud avec une porte sur son côté gauche, le lit prend place à son côté droit, la ruelle donnant sur les jardins. En tenant compte des éléments du pavillon, ceux des nouveaux devis ${ }^{44}$ puis des hypothèses respectant les préconisations architecturales de l'époque ${ }^{45}$, le mur sud, haut de 12 pieds 3 pouces 6 lignes $(4,01 \mathrm{~m})$, se composerait d'un pan de mur de 1 pied 1 pouce 6 lignes $(0,37 \mathrm{~m})$, de la porte de 2 pieds 6 pouces $(0,82 \mathrm{~m})$ pour 6 pieds 6 pouces de haut $(2,12 \mathrm{~m})$, d'un pan de mur de 3 pieds 1 pouce 6 lignes $(1,02 \mathrm{~m})$, de la cheminée de 4 pieds 6 pouces de large $(1,47 \mathrm{~m})$, de l'emplacement du lit prévu pour 6 pieds de côté $(1,96 \mathrm{~m})$ et enfin de la ruelle de 6 pieds 9 pouces $(2,2 \mathrm{~m})$.

En l'absence de tout inventaire du château de Versailles entre 1631 et 1643, on ne peut se faire une idée de l'aménagement et de la décoration du second appartement du roi. Seule la Gazette mentionne en 1634 un cadeau de la duchesse de Savoie, Christine, sœur $\mathrm{du}$ roi, pour meubler le château nouvellement reconstruit. Le marquis de SaintGermain, son ambassadeur, offre le 2 octobre 1634 au roi « 4 emmeublemens complets de velours à fonds d'argent, l'un bleu, l'autre gris de lin, le $3^{\mathrm{e}}$ verd et le $4^{\mathrm{e}}$ nacarat pour mettre en son chasteau de Versailles $»^{46}$. Ces précieux velours lamés argent, sans doute italiens, sont vraisemblablement des meubles d'hiver. Déjà couleur dominante dans le pavillon, le vert le reste tout autant dans le château : le placement du meuble vert dans la chambre de Louis XIII est en ce sens plausible. Un meuble similaire est d'ailleurs encore conservé à Versailles en 1666 :

Un emmeublement de velours vert à ramages fond et layne [lame] d'argent consistant en une tapisserie, un lit de repos, deux grands fauteuils et un petit, six sièges ployans et un tapis de table le tout garny de crespine et mollet d'argent. La dicte tapisserie composée de cinq pièces concistant en 34 léz de tour sur 2 aunes $2 / 3$ de hauteur, garnie d'un mollet d'argent doubliée de toille verte. Un lict de repos 
avec son traversin de mesme velours, deux matelas de satin vert et son bois, avec sa housse de serge de Londres verte. Deux carreaux de mesme velours garnis de frangeon d'argent avec leur housse de serge de Londres verte. Deux housses de fauteuils de mesme velours et garniture aveq leurs bois, aussi avec leur jousse. Un autre petit fauteuil de mesme velours avec sa housse. Six housses de sièges de mesme velours et garnitures avecq leurs bois et leur housse de serge. Un tapis de table à quatre pentes de mesme velours garnu de crespine et mollet d'argent avecq son bois et sa housse de serge ${ }^{47}$ (fig. 17, fig. 18).

\section{Figure 17}

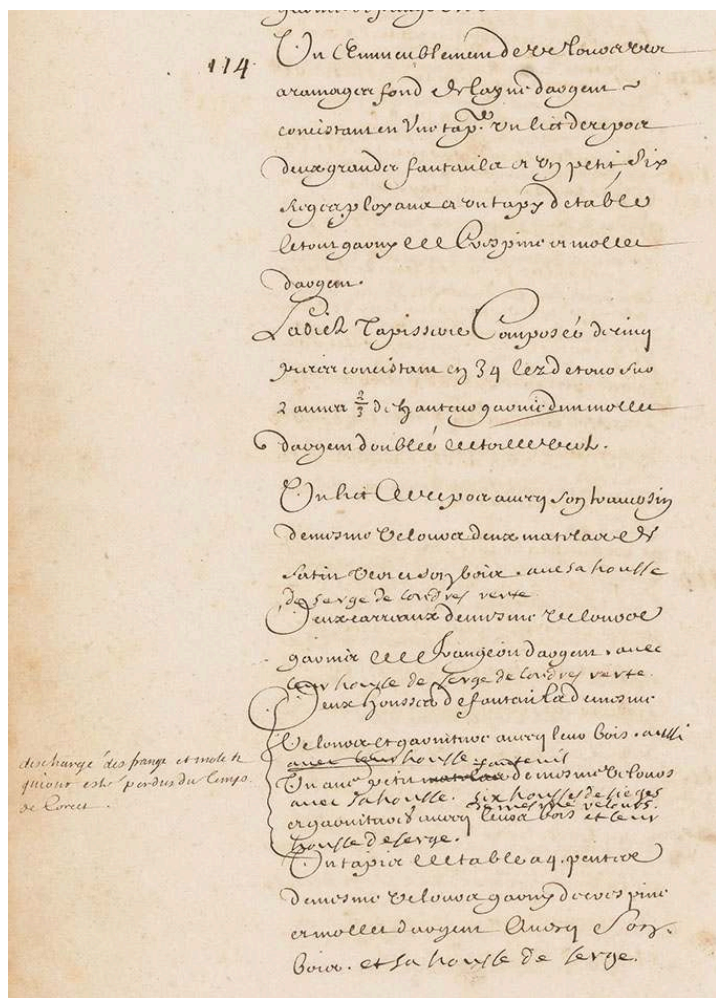

Inventaire des meubles du château de Versailles (1666-1684). AN, $\mathrm{O}^{1} 3450$, fol.68vº détail. (c) AN/pôle Image. 


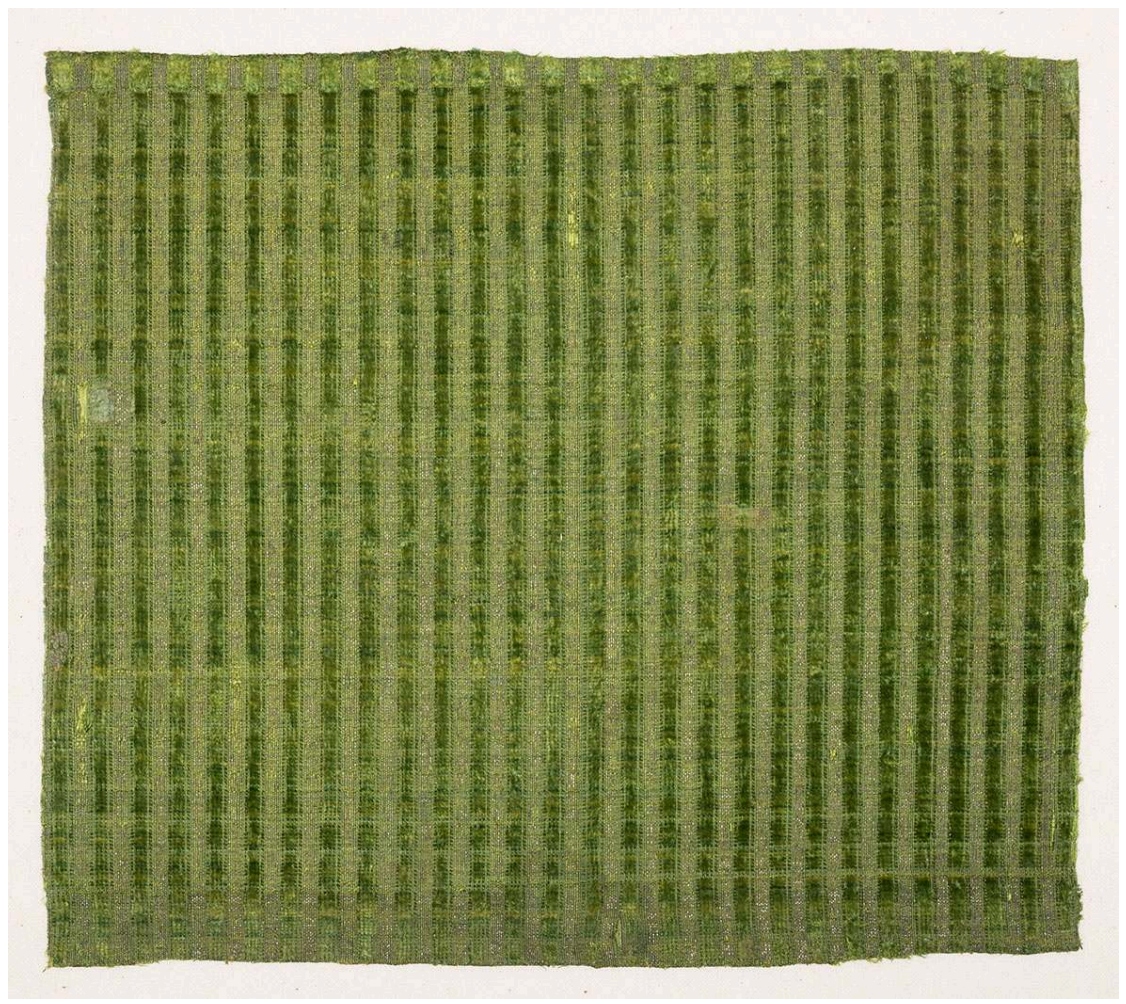

Fragment de velours vert lamé or, [fin du XVIe siècle-premier quart du XVIIe siècle]. Écouen, musée national de la Renaissance, no E.Cl. 11700.

(c) RMN-Grand Palais (musée de la Renaissance, château d'Écouen).

26 La présence d'un tapis de table induit celle d'une table et de son tapis de cuir pour permettre l'écriture. Les pièces de mobilier sont plus nombreuses et correspondent davantage à une chambre royale.

Les travaux n'ont pas été faits entièrement à l'économie, mais ce qui pouvait être conservé en architecture l'a été. C'est sans doute le cas aussi pour le mobilier. Outre le meuble, le mobilier se compose nécessairement d'une chaise percée installée au fond de la ruelle du lit. Les pliants sont alignés contre les murs. Un tapis recouvre le sol et la cheminée est munie de ses chenets de fer ou de laiton, de ses pincettes, pelle et tenaille. Enfin, si le premier valet de chambre dort dans la chambre du roi, sa couchette est sans doute installée à l'opposé du lit du roi, dans l'angle nord-est de la pièce où un espace suffisant reste disponible ${ }^{48}$. Mais peut-être dort-il dans le cabinet, comme c'était le cas dans le pavillon précédent.

\section{Lit du roi versus lit d'un roi}

$\mathrm{Du} 16$ février 1632 au 18 février 1643, Louis XIII vient régulièrement à Versailles lorsqu'il est dans les environs de Paris. Ses séjours sont assez brefs. Les plus courts tiennent sur la journée, pour une chasse ou un dîner. Le plus long, dix jours, est effectué du 21 au 31 octobre $1634^{49}$. La plupart durent entre deux et quatre jours. Le roi privilégie Saint-Germain-en-Laye, puis Chantilly et Versailles ${ }^{50}$. Celui-ci, qui forme souvent une parenthèse durant un séjour saint-germanois, se trouve à mi-chemin entre la résidence privée et un château pouvant désormais accueillir une partie de la Cour et 
des événements plus officiels. Ce double caractère, au cœur duquel se trouve la chambre du roi, est perceptible jusqu'au décès de Louis XIII. Son lit en est le symbole principal.

Le lit de Louis XIII au sein de son château versaillais participe à l'exercice du pouvoir royal, bien plus que dans le pavillon qui l'a précédé. Il trône dans une chambre plus vaste et au mobilier assorti plus abondant. Sa mise en valeur n'en est que plus évidente. La beauté de sa garniture de velours vert lamé argent le confirme encore. Versailles, résidence privée, est dans les faits tout autant une résidence royale. Lorsque le roi donne des soupers d'après chasse avec les principaux seigneurs de la Cour en janvier 1642 et en février 1643, nul doute que des membres de la Cour sont nombreux jusque tard le soir auprès du lit du roi ${ }^{51}$. À côté de la vie de cour ordinaire, Versailles est aussi le cadre d'une vie diplomatique réelle. La date la plus marquante est le dîner offert le 25 février 1636 à Édouard Farnèse, duc de Parme et de Plaisance, en visite en France $^{52}$. Louis XIII ne peut le recevoir, selon le cérémonial, que sur le seuil de sa chambre. Le roi reçoit aussi régulièrement des ambassadeurs ou des envoyés, également dans sa chambre ${ }^{53}$. D'autres audiences sont accordées à Versailles. Elles ne peuvent se tenir que dans la chambre : un fauteuil toujours placé dos à la cheminée ou sous le dais, si ce dernier est toujours présent. Les grands du royaume sont reçus les 7 et 8 août $1632^{54}$. Le 26 mai 1637, le Conseil est présent pour l'audience accordée au parlement de Paris. Depuis son cabinet où il est avec les membres du Conseil, le roi attend la délégation qu'il reçoit dans sa chambre ${ }^{55}$.

Mais Versailles reste un château privé aux yeux du roi et des contemporains. Le financement du chantier par les Menus-Plaisirs et non les Bâtiments du roi le confirme. $\mathrm{Au}$ moins à six reprises, Versailles incarne pleinement le refuge recherché par le roi. Étant donné son caractère et l'aménagement intérieur, ce refuge ne peut être que sa chambre et son cabinet. L'occasion la plus manifeste date de mai 1637. Louis XIII se retire à Versailles après l'entrée en religion de son amie Louise de La Fayette, chez les Visitandines de Chaillot. "Dès que $\mathrm{M}^{\text {lle }}$ de La Fayette fut partie pour le couvent, le roi tomba dans une profonde mélancolie : il se fit conduire à Versailles, où il fut obligé de se mettre au lit : il lui prit un dégoût et une tristesse qui fit craindre pour sa santé. Le cardinal [de Richelieu] l'étant venu voir, le trouva si abbattu qu'il en fut effrayé $»^{56}$. Le lit de Louis XIII est son havre ultime à Versailles.

31 Concernant la vie quotidienne autour du lit, rien ne permet de penser qu'elle diffère de celle menée dans le pavillon. Le seul élément pertinent est relevé par le père Griffet qui expose pourquoi début décembre 1637, surpris par un orage alors qu'il rendait visite à Louise de La Fayette (sœur Angélique) dans son couvent, Louis XIII rejoint le Louvre. En effet, «il ne lui fut pas possible de retourner à Versailles ni d'aller à Saint-Maur où sa chambre, son lit et les officiers de sa bouche étaient arrivés [...] son appartement au Louvre n'était point tendu $»^{57}$. Derrière cette anecdote bien connue de la soirée du 5 décembre 1637 qui précède de neuf mois la naissance de Louis XIV, retenons les éléments propres à la vie quotidienne du roi. Suivant les besoins, un lit peut être attaché à une résidence, comme l'était celui de Versailles en septembre 1630 lors de son inventaire, alors que le roi devait au même moment se servir d'un meuble de campagne pour son déplacement vers Lyon et le Piémont. Un lit peut aussi l'accompagner pour des trajets limités, comme ici autour de Paris. Mais le nécessaire à la charge du personnel de la Chambre précède le roi pour que tout soit prêt à son arrivée. En cas 
d'imprévu, si la destination convenue ne peut être atteinte, trouver un nouveau logement pour la nuit est impératif.

Dans ce château privé, où le roi aime se retirer ou partir à la chasse, le lit de Louis XIII rappelle par la composition de son meuble le statut royal de la chambre. Même si le meuble lui confère un caractère plus précieux que ne l'était la chambre du pavillon, elle conserve le cadre sobre et intime souhaité par son occupant.

\section{Entre sobriété et majesté}

Disposer d'une résidence privée modeste, loin de la Cour, où il ne serait entouré que de quelques proches partageant sa passion cynégétique, fut l'un des objectifs premiers du jeune roi $^{58}$. La chambre du maître des lieux doit cependant symboliser la continuité dynastique et son pouvoir royal grâce au lit et au dais. La circulation du visiteur confirme combien la distribution intérieure et la place du lit sont liées. Dans le pavillon, le lit de damas vert est à l'aune de cette maison des champs et des goûts sobres du roi : certes, un dais est présent mais la chambre n'est pas précédée d'une antichambre et le lit ne compte ni estrade ni balustrade. La chambre du château, élargie et très lumineuse, met parfaitement en valeur le riche lit habillé de velours vert lamé argent, et dont le meuble est enrichi d'un plus grand nombre de pièces de menuiserie. Tout en conservant un décor sobre, ce lit accompagne la mutation de Versailles après la journée des Dupes et la définitive affirmation du pouvoir de Louis XIII (fig. 19).

Figure 19

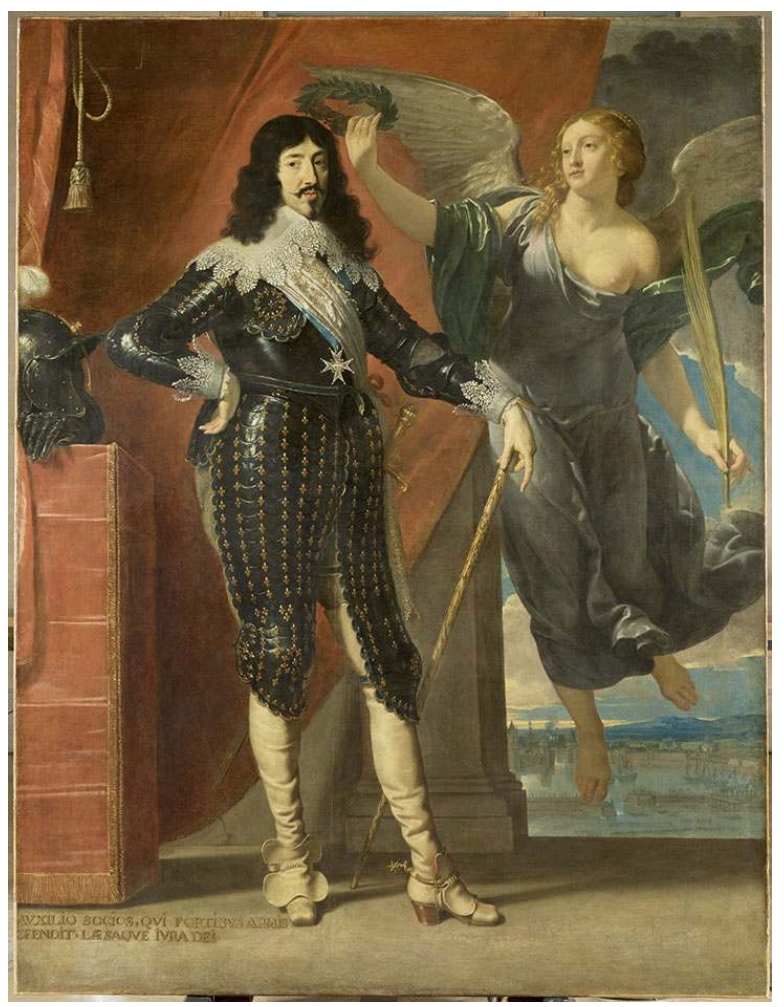

Louis XIII couronné par la Victoire par Philippe de Champaigne, 1635. Paris, musée du Louvre, INV 1135. (c) RMN-Grand Palais (musée du Louvre). 
Les lits de Louis XIII à Versailles reflètent son constant « sens inné de la majesté et de la dignité royale [...] pour la gloire de la France $\aleph^{59}$ couplé à son désir de simplicité et de relatif retrait. En effet, ils forment une synthèse et un manifeste du statut à la fois privé et royal du Versailles voulu Louis XIII. Ils assument par là la rencontre entre l'intime et l'universel. Enfin, au-delà du seul dessein versaillais de Louis XIII, ils sont, grâce à leur composition, leurs usages et leurs charges symboliques les premiers jalons, discrets mais réels, d'une histoire de la majesté royale à Versailles.

\section{NOTES}

1. - Cet article est issu des recherches de l'auteur dans le cadre d'une thèse d'histoire à soutenir à Sorbonne Université, sous la direction de Lucien Bély, consacrée aux chambres du roi à Versailles de 1623 à 1789.

2. - SAINT-SIMON, Louis de Rouvroy, duc de. Mémoires. Éd. Yves Coirault. Paris : Gallimard, 1982-1990, I, 1691-1701, 1982, p. 509.

3. - PETITFILS, Jean-Christian. Louis XIII. Paris : Perrin, 2008, p. 302.

4. - HÉROARD, Jean. Journal de Jean Héroard. Éd. Madeleine Foisil. Paris : Fayard, 1989, vol.1, 1601-1608, p. 1354.

5. - LE GUILLOU, Jean-Claude. Versailles avant Versailles : au temps de Louis XIII. Paris : Perrin, 2011, p. 77-90.

6. - BERNARD, Charles. Histoire du roy Louis XIII. Paris : chez Augustin Courbé, 1646, $2{ }^{\mathrm{e}}$ partie, p. 226.

7. - Sur l'architecture du Versailles de Louis XIII, les travaux de Jean-Claude Le Guillou sont fondateurs.

8. - HÉROARD, J. Éd. cit., vol. 1, 1601-1608, p. 1287 et vol. 2, 1609-1628, p. 2489, p. 2597, 2651-2652 et 2740.

9. - Ibid., vol. 2, p. 2891.

10. - Louis XIII dort au château et non dans une auberge ou une quelconque maison du bourg, car l'envoi de son lit parisien n'aurait pas été nécessaire : des lits sont présents et celui du roi, même avec le format plus réduit des lits dits « de campagne ", n'aurait pas été adapté. Enfin, l'ancien manoir est loué.

11. - HÉROARD, J. Éd. cit., vol. 2, p. 2913-2914.

12. - AN, MC/XIV/ et MC/XIX-402-403; AD Yvelines, B 3586.

13. - LE MUET, Pierre. Manière de bastir pour touttes sortes de personnes. Paris : Melchior Tavernier, 1623 ; SAVOT, Louis. L'Architecture française des bastimens particuliers. Paris : Sébastien Cramoisy, 1624. Ces deux ouvrages pratiques connaissent une forte diffusion, voir THORNTON, Peter. L'Époque et son style: la décoration intérieure (1620-1920). Paris: Flammarion, 1986, p. 15 ; LE GUILLOU, Jean-Claude. Op. cit., p. 99-100.

14. - La première chambre de Louis XIII correspond aujourd'hui à la partie nord de l'antichambre de l'œil-de-Bœuf.

15. - La cheminée d'une chambre n'est pas au centre du mur et doit être décalée de 2 pieds à l'opposé du lit (LE MUET, Pierre. Op. cit., p. 2 et SAVOT, Louis. Op. cit., p. 85-86). On constate ici en partie la permanence de l'usage prôné par les traités d'architecture du XVI ${ }^{\mathrm{e}}$ siècle, au premier rang desquels ceux de Sebastiano Serlio, Jacques Androuet Du Cerceau et Philibert Delorme, voir 
CHATENET, Monique. " "Cherchez le lit" : la place du lit dans la demeure française au XVI ${ }^{\mathrm{e}}$ siècle ». Édité en ligne sur Cour de France.fr le 2 novembre 2008: http://cour-de-france.fr/ article651.html [consulté le 04/07/2019].

16. - Voir infra pour cette dimension.

17. - AD Yvelines, B 3586. Toutes les citations qui suivent sont issues des fol. $2,7 \mathrm{r}^{\circ}-\mathrm{v}^{\mathrm{o}}$ et $9 \mathrm{v}^{\mathrm{o}}$.

18. - CASTELLUCCIO, Stéphane. Le Style Louis XIII. Paris : Éd. de l'Amateur, 2002, p. 72.

19. - $\mathrm{AN}, \mathrm{O}^{1} 3450$, fol. $61 \mathrm{v}^{\circ}-62, \mathrm{n}^{\circ} 67$; $\mathrm{AN}, \mathrm{O}^{1} 3331$, fol. $45, \mathrm{n}^{\circ} 208$, éd. GUIFFREY, Jules. Inventaire général du mobilier de la Couronne sous Louis XIV (1663-1715). Paris : J. Rouam, 1885-1886, t. 2, p. 233, $\mathrm{n}^{\circ} 208$. L'hypothèse retenue est qu'il s'agit toujours du bois d'origine.

20. - SAVOT, Louis. L'Architecture..., p. 88 ; CASTELLUCCIO, Stéphane. Op. cit., p. 34.

21. - Voir dans la base Mérimée : notice PA00102852.

22. - CASTELlUCCIO, S. Op. cit., p. 117 ; THORNTON, Peter. Op.cit., p. 19. Voir aussi COURTIN, Nicolas. L'Art d'habiter à Paris au XVII' siècle : l'ameublement des hôtels particuliers. Djion : Faton, 2011.

23. - SAINT-SIMON. Mémoires. Éd. cit., V, 1714-1716, 1985, p. 522.

24. - HÉROARD, Jean. Éd. cit., vol. 2, p. 2921.

25. - Ibid., vol.2, p. 2914, 2938, 2965, 2967, 2969, 2973, 2978-2979, 2984-2985, 2987-2988 et 3014-3015. Le potus divinus est une boisson « d'eau cuitte sucrée et jus de limon ou citron », voir PARÉ, Ambroise. CEuvres complètes. Éd. Joseph-François Malgaigne. Paris : J.-B. Baillière, 1840, t. 2, p. 34).

26. - CASTELLUCCIO, S. Op. cit., p. 33.

27. - Sieste réparatrice de $11 \mathrm{~h}$ à midi après une chasse matinale ou repos après un trajet matinal depuis Rambouillet (HÉROARD, J. Éd. cit., vol. 2, p. 2930 et 2935).

28. - PETITFILS, Jean-Christian. Op. cit., p. 423.

29. - HÉROARD, J. Éd. cit., vol. 2, p. 3014-3015.

30. - BRIENNE, Henri-Auguste de Loménie, comte de. Mémoires. Dans Nouvelle collection des mémoires pour servir à l'histoire de France, $3^{\mathrm{e}}$ série, t. 3. Paris : Éd. du commentaire analytique du Code civil, 1838, p. 30-31; GRIFFET, Henri. Histoire du règne de Louis XIII, roi de France et de Navarre. Paris: Les Libraires associés, 1758, t.1, p. 425; HÉROARD, J. Éd.cit., vol. 2, p. 3014-3015; MALHERBE, François de. CEuvres complètes. Éd. Ludovic Lalanne. Paris : Hachette, 1862-1869, t. 3, p. 580.

31. - Au moins trois : son demi-frère Alexandre de Vendôme, grand prieur de Saint-Jean-deJérusalem fin mai 1626, Claude Bouthillier, secrétaire des commandements de la reine-mère, fin février 1628, et les princes du sang le 30 octobre 1630.

32. - HÉROARD, J. Éd. cit., vol. 2, p. 2984 ; Mercure français, t. 13, p. 411-412 ; RICHELIEU, ArmandJean du Plessis de. Les Papiers de Richelieu : section politique intérieure, correspondance et papiers d'État. Éd. Pierre Grillon. Paris : A. Pedone, 1975-1977, t. II, 1627, p. 191.

33. - ARNAULD D'ANDILLY, Robert. Journal inédit (1620-1632). Éd. Eugène et Jules Halphen. Paris : Jouaust et Champion, 1888-1909, t.3, p. 39-40 ; Mercure français, t. 13, p. 380-382 ; RICHELIEU, Armand-Jean du Plessis de. Mémoires du cardinal de Richelieu sur le règne de Louis XIII depuis 1610 jusqu'à 1638. Dans Nouvelle collection pour servir à l'histoire de France, $2^{\mathrm{e}}$ série, t. 7-9, éd. JosephFrançois Michaud et Baptistin Poujoulat. Paris : Éd. du commentaire analytique du Code civil, 1837-1838, t. 7, p. 424-425.

34. - La Courneuve, Archives MEAE, Mém. et Doc., France, vol. 787, fol. $44 \mathrm{v}^{\circ}-45$; Mercure français, t. 13, p. 380-383.

35. - VALDORY, Guillaume de. Anecdotes du ministère du cardinal de Richelieu et du règne de Louis XIII... traduites du Mercurio de Vittorio Siri. Amsterdam : Jean Muzier, François Barrois, 1717, t. 1, p. 244-246.

36. - BASSOMPIERRE, François de. Journal de ma vie: mémoires du maréchal de Bassompierre. Éd. Audoin de Chantérac. Paris : Vve Renouard, 1870-1877, t. 4, p. 125-126. 
37. - RICHELIEU, Armand-Jean du Plessis de. Lettres, instructions diplomatiques et papiers d'État du cardinal de Richelieu. Éd. Denis-Louis-Martial Avenel. Paris: Impr. impériale puis nationale, 1853-1877, t. 4, 1630-1635, 1861, p. 11-12.

38. - DELORME, Philibert. Le Premier Tome de l'architecture. Paris : Fédéric Morel, 1567, fol. 18.

39. - BnF, Est., Topographie de la France, Va 78e, t. 2, B 9000 ; musée national des Châteaux de Versailles et de Trianon, INV.GRAV 5663.

40. - Toutes les données architecturales sont issues des devis cités ci-dessus et des recoupements possibles avec les mesures du pavillon.

41. - Leurs dispositions et leurs volumes ne correspondent plus aux pièces agrandies. Quatre plans des années 1661-1667 tendent à confirmer les modifications d'emplacement des cheminées et portes uniquement lors des premiers travaux de Louis XIV (BnF, Est., Topographie de la France, Va 78e, t. 1, B 8916 ; Bibl. de l'Institut, ms. 1307, nº 68 ; BnF, Est., Va 422, H 186481 ; musée national des Châteaux de Versailles et de Trianon, INV.GRAV 1716).

42. - Aujourd'hui, la seconde chambre de Louis XIII correspond à la partie nord du cabinet du Conseil.

43. - LE MUET, Pierre. Op. cit., p. 2 ; SAVOT, Louis. Op. cit., p. 85.

44. - AN, MC/XIX/402-403.

45. - LE MUET, Pierre. Op. cit. ; SAVOT, Louis. Op. cit.

46. - Gazette $\mathrm{n}^{\circ} 112$ du 21 octobre 1634, p. 456 ; Gazette $\mathrm{n}^{\circ} 106$ du 7 octobre 1634, p. 432 ; Mercure français, t. 20, 1634, p. 742-743.

47. - AN, $\mathrm{O}^{1} 3450$, fol. $68 \mathrm{v}^{\circ}$ : meuble $\mathrm{n}^{\circ} 114$; AN, $\mathrm{O}^{1} 3331$, t. 2, fol. 50 ; GUIFFREY, Jules. Op. cit., t. 2 , p. 237, meuble $n^{\circ} 255$. Les deux carreaux sont entreposés au garde-meuble du château en 1708 (AN, $\mathrm{O}^{1} 3445$, fol. 112). On peut noter à titre d'exemple la conservation au château d'Écouen d'un fragment de velours vert datant de la fin $\mathrm{du} \mathrm{XVI}^{\mathrm{e}}$ ou du premier quart du XVII ${ }^{\mathrm{e}}$ siècle, lamé or et non argent : Écouen, musée national de la Renaissance, $n^{\circ}$ E.Cl. 11700 (voir fig. 18).

48. - SAVOT, Louis. Op. cit., p. 89.

49. - Gazette $\mathrm{n}^{\circ} 115$ du 28 octobre 1634, p. 468 ; Gazette $\mathrm{n}^{\circ} 117$ du 4 novembre 1634, p. 476 ; Gazette $\mathrm{n}^{\circ} 131$ du 30 novembre 1634, p. 529-532; Mercure français, t. 20, 1634, p. 877-890; Louis XIII. Louis XIII d'après sa correspondance avec le cardinal de Richelieu. Éd. Raymond de Beauchamp. Paris : H. Laurens, 1902, p. 158.

50. - LENET, Pierre. Dans Nouvelle collection des mémoires pour servir à l'histoire de France, éd. cit., t. 2 , p. 457.

51. - Gazette $n^{\circ} 6$ du 11 janvier 1642, p. 700 et Gazette $n^{\circ} 23$ du 21 février 1643, p. 151.

52. - Gazette $\mathrm{n}^{\mathrm{o}} 33 \mathrm{du} 1^{\mathrm{er}}$ mars 1636, p. 132.

53. - Sept audiences ont lieu : Venise et Hollande en 1634 (Gazette $\mathrm{n}^{\circ} 115$ du 28 octobre 1634, p. 468), Hollande et Savoie en 1636 (Louis XIII. Louis XIII d'après sa correspondance..., éd. cit., p. 228 et p. 244), Saint-Siège en 1639 (Gazette $\mathrm{n}^{\circ} 24$ du 26 février 1639, p. 116) et Savoie et Saint-Siège en 1642 (Gazette $\mathrm{n}^{\circ} 104$ du 16 août 1642, p. 700 et Gazette $\mathrm{n}^{\circ} 20$ du 14 février 1643, p. 132).

54. - Gazette du 13 août 1632, p. 325-326.

55. - Gazette no 80 du 30 mai 1637, p. 324 ; GRIFFET, Henri. Op. cit., t. 2, p. 818 ; MOLÉ, Mathieu. Mémoires de Mathieu Molé, procureur général, premier président au Parlement de Paris et garde des sceaux. Éd. Aimé Champollion-Figeac. Paris : Jules Renouard, 1855-1857, t. II, 1629-1641, 1855, p. 379-381.

56. - Gazette $\mathrm{n}^{\circ} 76$ du 23 mai 1637, p. 308 ; GRIFFET, Henri. Op. cit. t. 3, p. 13-14.

57. - Ibid., p. 101.

58. - Il a vingt-deux ans en 1623.

59. - PETITFILS, Jean-Christian. « Louis XIII, un grand roi méconnu ». Versalia, $n^{\circ} 13,2010$, p. 171. 


\section{RÉSUMÉS}

Les lits de Louis XIII à Versailles ne sont pas les plus connus de l'histoire du château. Pourtant, même sans représentation iconographique, des sources archivistiques et imprimées permettent de les évoquer et d'étudier leurs usages et symboliques. À Versailles, conçu par Louis XIII comme un havre personnel, le lit, symbole de continuité dynastique, réunit le statut royal du propriétaire et sa recherche d'une sobre retraite. Louis XIII fait bâtir un pavillon en 1623. Cette «maison des champs » est agrandie et sa distribution revue au début des années 1630, offrant au roi deux chambres successives. La première, dépourvue d'antichambre, accueille un meuble de damas vert aux franges de soie verte et d'or mis en valeur par la simplicité de la décoration de la pièce et son mobilier réduit. La seconde, avec antichambre, plus vaste et lumineuse, reçoit un précieux meuble de velours italien vert lamé argent. Par leurs usages au fil des séjours du roi, ces deux chambres accompagnent la mutation de Versailles dans la géographie du pouvoir à partir des années 1630 : leurs lits sont une synthèse révélatrice du statut à la fois privé et royal du Versailles de Louis XIII.

Louis XIII's beds at Versailles are not the best-known ones in the history of the palace. No pictures of them survive but other archival and printed sources allow us to analyse them and to study their usages and symbolic values. The Versailles conceived by Louis XIII was a personal haven where the bed symbolised dynastic continuity, bringing together the royal status of its owner and his quest for a sober retirement. Louis XIII had a modest pavilion built at Versailles in 1623, a 'countryside dwelling' which was enlarged and reorganised at the beginning of the 1630s, offering the King two successive bedrooms. The first one, without any antechamber, accommodated a bed upholstered in green damask with fringes in green silk and gold, set off by the simplicity of the room's decoration and the sparseness of its furniture. The second bedroom had an antechamber and was larger and more luminous. It housed a more precious bed of green Italian velvet with silver lame. Through their occupation during the King's presence at Versailles, these two bedrooms accompany the transformation of the palace in the geography of power from the 1630s. The beds can be seen as a revealing synthesis of the status of Louis XIII's residence at Versailles, private and royal at one and the same time.

\section{INDEX}

Keywords : apartment, chamber, bedroom, chimney, canopy, damask, Philibert Delorme (architect), Jean Héroard (royal surgeon), Pierre Le Muet (architect), Philibert Le Roy (architect), bed, Louis XIII, Marie de Médicis, furniture, Pennautier, Louis Savot (architect), velvet, Versailles Mots-clés : appartement, chambre, cheminée, dais, damas, Philibert Delorme (architecte), Jean Héroard (premier médecin), Pierre Le Muet (architecte), Philibert Le Roy (architecte), lit, Louis XIII, Marie de Médicis, meubles, Pennautier, Louis Savot (architecte), velours, Versailles

\section{AUTEUR}

\section{VIVIEN RICHARD}

Archiviste paléographe, conservateur du patrimoine, Archives nationales vivien.richard@culture.gouv.fr 